\title{
Participatory Action Research in Higher Education Training
}

\author{
Sandro Serpa ${ }^{1}$, Carlos Miguel Ferreira ${ }^{2}$, Ana Isabel Santos ${ }^{3}$, Ricardo Teixeira ${ }^{4}$ \\ ${ }^{1}$ University of the Azores, Faculty of Social Sciences and Humanities, Department of Sociology; Interdisciplinary \\ Centre of Social Sciences - CICS.UAc/CICS.NOVA.UAc, and Interdisciplinary Centre for Childhood and Adolescence \\ - NICA - UAc, Portugal \\ ${ }^{2}$ Polytechnic Institute of Castelo Branco, Estoril Higher Institute for Tourism and Hotel Studies, Interdisciplinary Centre \\ of Social Sciences - CICS.NOVA, Portugal \\ ${ }^{3}$ University of the Azores, Faculty of Social Sciences and Humanities, Department of Education, Interdisciplinary \\ Centre for Childhood and Adolescence - NICA - UAc, and CIE (Center for Educational Research) - ISPA, Instituto \\ Universitário, Portugal \\ ${ }^{4}$ University of the Azores, Faculty of Sciences and Technology, Department of Mathematics and Statistics, \\ Interdisciplinary Centre for Childhood and Adolescence - NICA - UAc, Portugal \\ Correspondence: Sandro Serpa, University of the Azores, Faculty of Social Sciences and Humanities, Department of \\ Sociology, Portugal. E-mail: sandro.nf.serpa@uac.pt
}

Received: February 23, 2018

Accepted: April 15, $2018 \quad$ Available online: May 18, 2018

doi:10.11114/ijsss.v6i6.3286

URL: https://doi.org/10.11114/ijsss.v6i6.3286

\begin{abstract}
By fostering a direct engagement of those involved in solving problems or needs in a context of real situations, participatory action research (PAR) offers great potentialities for the academic training of future and even current professionals. However, there is a weak implementation of PAR as a pedagogical training strategy in higher education. Hence, this paper seeks to be a contribution to answering the following question: What potentialities and challenges can arise from the implementation of PAR in higher education? To this end, the following elements are addressed: what PAR consists of, and the contributions it can offer for higher education training, concluding with the presentation of some challenges and difficulties that seem to emerge from the use of PAR at the institutional, students and teachers' levels, and which may help understanding its little use.
\end{abstract}

Keywords: participatory action research, training, learning, teaching, higher education, professional development

\section{Introduction}

Until rather recently, action research was little touched upon and even less implemented. Having a reduced visibility, it appeared to be the poor methodological relative in social sciences, either in Portugal or even at the international level (Almeida, 2001; Costa \& Machado, 1987; Esteves, 1986). Even today, action research is not much considered, reputed or practiced at the academic level (Smith, 2017), although it appears to be gaining ground in some higher education contexts, albeit in a very limited way (Mendonça, Cotta, Lelis, \& Junior, 2015; Zhang \& Amundsen, 2015).

In this sense, Esteves (1986) maintains that there is a silence on action research, as a rule, given that it flees from the orthodoxy of the methodology considered as consensually legitimate, which may happen also because

Action research aims to rethink both the nature of inquiry and who participates in it. In traditional, nomothetic, social-scientific educational research - with its founding trope of the data-collecting, distantiated knower wielding methods to fend off bias and randomness - teachers show up only as subjects (though, in a case of language as wish-fulfillment, we call them 'participants') (Higgins, 2016, p. 233).

However, at present, numerous researchers fight this penumbra ascribed for so long to action research. Currently, action research has several designations, with distinct proposals for ways of materialisation (Almeida, 2001; Balakrishnan \& Claiborne, 2017; Corpa, Hito, \& Garcia, 2010; Kindon \& Elwood, 2009; Moch, Vandenbark, Pehler, \& Stombaugh, 2016; Schneider \& Daddow, 2017), as well as variants, for example, at the level of stakeholders' participation. Yet, in general, it may be considered that action research entails articulating research with intervention, especially in several cycles or stages of enhancement or improvement (Costa \& Machado, 1987). 
Action research consists, thus, of a methodological strategy, the use of which is geared by the existence of the following moments: the assessment of a problem or need for improvement; the definition of an intervention strategy; the implementation of an intervention; the monitoring of that intervention; the assessment of the results attained in the new situation created; and the new application of this process, if deemed necessary, according to the assessment of the aforementioned final moment (see, for example, Arends, 1999; Strode, 2013).

In this context, Esteves (1986) refers to three types of concomitant objectives in action research: research (production of knowledge about reality); innovation (introduction of changes in a situation); and training of competences (participants' social learning process), understanding it as

[...] a collective process that establishes new rules of action, with repercussion both in the community of researchers and technicians and in the groups, institutions and populations under study, as well as in the bureaucratic institutions involved and in the reciprocal relationship between them (p. 271).

The type of action research this essay will focus on seeks to encourage the participation of all stakeholders in this process. This is the participatory action research (PAR), through which each individual, as a participant, plays an active and generally conscious and critical role in the action-research process (Jacobs, 2016; Strode, 2013). This PAR research, which promotes the participation of stakeholders, will be the centre of the reflection that follows.

PAR has been studied and implemented in several sectors of reality. Among the many examples that could be presented, the following are highlighted: in the monitoring of social reintegration of young mothers associated with armed groups (Worthen, Onyango, Wessells, Veale, \& McKay, 2013); in the education of young people at risk (Iwasaki, Hopper, \& Whelan, 2017); in teachers' professional development (Yigit \& Bagceci, 2017); in the engagement of nurses and local leaders in the formation of the research network (Asuquo \& Etowa, 2016); in the participation of stakeholders, including disabled people, in disability and community issues (Higashida, Kumara, \& Illangasingha, 2015); in the development of prospective teachers' professional independence during their pedagogical practice (Strode, 2013); in environmental education projects (Lewis, 2004); or also in the development of a course module on education for sustainable development in pre-service chemistry teacher education (Burmeister \& Eilks, 2013).

PAR is an advantageous training strategy by fostering a direct engagement of those involved in solving problems in a context of real situations, through grounded empirical research, inasmuch that it offers great potentialities in the training of future and even current professionals in the higher education context. However, there is a weak implementation of PAR as a training strategy in higher education. Therefore, this paper seeks to answer the following question: what potentialities and challenges can arise from the implementation of PAR in higher education? To this end, the following elements are addressed: what PAR consists of, the contributions that it can offer to training in the higher education context, grounding our stance on the need for this methodological strategy to be more pedagogically implemented in training programs. The paper ends with the discussion of some challenges and difficulties centred on students, teachers and institutions that seem to help understanding its little use.

\section{Participatory Action Research}

After all, what is PAR? As a variant or field of action research (Santos, 2016), PAR is defined by the direct and active involvement of all stakeholders in the research process, with the aim to solve a problem, a need, or to improve a situation, in a collaborative and democratic way (Jacobs, 2016). There is no dichotomy both in PAR and in its different phases between the role played by the researcher as opposed to the role of sheer respondents, in a true process of collaborative learning (Balakrishnan \& Claiborne, 2017; Kindon \& Elwood, 2009):

Participatory research processes aim to develop participants' voices and actively involve them in transforming education. They also speak to a broader responsibility that educational research has to influence human development through including elements of participation as opposed to doing research 'on' or 'about' the participants (Walker \& Loots, 2017, p. 168).

In this logic, Asuquo and Etowa (2016) put forward some principles that gear the use of PAR (in accordance with Kemmis \& McTaggart's, 2005): a social process, by necessarily involving individuals in the context of social relationships; participatory, with the engagement of all involved in the research process; practical and collaborative, in the reconstruction of interactions and social practices; emancipatory, providing the participants with knowledge and tools to raise awareness of constraining social structures, as well as strategies for self-development and self-determination; critical, clarifying the power relationships that shape the world and social relationships; reflexive, through a self-critical process of action and reflection; and aims to transform both theory and practice, in close articulation with each other.

However, it should be stressed that PAR is a concept that has its own specificities and subtleties that emerge in the higher education training context. 


\section{PAR in Higher Education Training}

In higher education training, encouraging active student learning is increasingly considered necessary (Burmeister \& Eilks, 2013; Ito, 2017; Radloff, Joslyn, \& Capobianco, 2016) in the development of students' "ability of reflecting thinking and problem solving" (Sivaci, 2017, p. 21), as considered by Sivaci in pre-service teachers training. This principle can be generalised to any scientific area, in our opinion. It should be noted that

Practical training included in the initial training period should allow the future teacher to:

1. Identify him/herself as a teacher and the teaching styles s/he is able to use by studying the class environment and the effects that these styles produce on students.

2. Be able to identify the problems of work organisation in the classroom, with the aim to make it productive. The problems of discipline and class organisation are the acutest ones during the first year of professional practice.

3. Be able to solve the problems arising from teaching-learning activities, seeking to make educational contents accessible to each of his/her students (Esteve, 2003, p. 119).

The mobilisation of PAR can contribute to fulfilling this aim and, in this sense, it can contribute to improving the quality of education offered in the higher education context (Balakrishnan \& Claiborne, 2017; Barbre \& Buckner, 2013; Burmeister \& Eilks, 2013; Kindon \& Elwood, 2009; Mendonça et al., 2015; Strode, 2013; Vikstrom, Bostrom, \& Johannsen, 2016; Young, 2017). For example, in the training of future teachers,

[...] the incorporation of action research would give the student teachers an opportunity to gain a deeper understanding of the subject area, their own teaching style, areas that are strong, and also those that need improvement. This is the precursor for what teachers are expected to be able to continually do when they enter the profession (Barbre \& Bucker, 2013, p. 5).

The implementation of PAR in the higher education training context involves the mobilisation of several interacting elements (Strode, 2013):

(1) its objective is to understand professional practice deeper, enrich the capacity of involved participants and their opportunities to make inquires for improvement of quality; (2) in the research of professional practice, subjects explore themselves (in cooperation with each other and the others); (3) research is critically informative, active, action-oriented; (4) the result of professional practice research is not an ultimate achievement. It is a way of thinking about teaching and learning to facilitate endless improvements (p. 88).

Considering the aforementioned studies, why is PAR, then, not more mobilised in training in the higher education context? (Walker \& Loots, 2017). We will, thus, present a contribution to the understanding of some of the potential challenges arising from the implementation of PAR in higher education.

\section{Challenges to the Implementation of PAR in Higher Education}

The implementation of PAR in the higher education context, even considering the need for a more successful, effective and efficient teaching, through a perspective of student-centred constructivist learning (Altun \& Yücel-Toy, 2015; Strode, 2013), is a very complex process that challenges the more traditional perspectives of teaching: "The knowledge construction and interpersonal interaction of PAR in university education is socially and politically complicated, just as it is in any 'field work'. Incorporating PAR into our teaching and graduate supervision can add further ethical, political and logistical challenges" (Kindon \& Elwood, 2009, pp. 23-34).

Given that there are several factors to be considered for a successful PAR process, as can be seen in the literature, for example,

The implementation of the model can be threatened by insufficiency of student's experience and pedagogical skills; inadequate student's self-evaluation; lack of motivation; insufficiency of support and encouragement during practice; changes induced by subjective and objective factors in the objectives of individual and study programme development (Strode, 2013, p. 88),

next section offers an analysis of the several challenges that the application of PAR can raise in the specific situation of (self)training of higher education students, which translate into barriers and hindrances, both for students and teachers, and, even, of an institutional nature.

\subsection{For Students}

With regard to students, the following factors involved in the implementation of PAR in a training context will be addressed: students' preparation and expectation; control of the work to be carried out by students; students' assessment and self-assessment; and finally, the changes caused by the uncertainty generated by a PAR dynamics process. 
In terms of students' preparation and expectations, it may be insufficient (Strode, 2013), which implies the need for a successful initial framework. It also implies fleeing from the existing orthodoxy (Vaughan \& Burnaford, 2016), leading to the need for greater self-control of the work to be carried out by students, regarding the type, quality and quantity of this work, which may generate overwork and/or be considered meaningless by students (Kindon \& Elwood, 2009; Marchand, 2017).

Concerning students' assessment and self-assessment (Altun \& Yücel-Toy, 2015; Strode, 2013), in a culture centred on "cultures of valuation" (Downs, 2017), the assessment of the process and outcome of PAR, even when contributing to the improvement of the teaching practice (Strode, 2013), has its own specificities that may translate into increased difficulties in the context of the implementation of PAR.

Finally, the changes brought about by the uncertainty generated by a PAR training process and by its own dynamics (Strode, 2013) are yet another factor that adds to the uncertainty that students may feel (Kindon \& Elwood, 2009; Marchand, 2017). These changes can collide with preconceived ideas/expectations of both teachers and students, generating feelings of discomfort and anguish on both sides, especially at the beginning of this process (Kindon \& Elwood, 2009). These feelings are often shared by the students themselves, for example, in the writing of the thesis, when faced with the difficulty of not being able to fulfil the traditional canons of an academic thesis (Smith, 2017), which has implications for students' assessment.

On the other hand, it is natural for some students to face difficulties in understanding the difference between research and PAR, which can be clarified throughout the development of PAR, through intense collaboration among all and through feedback provided by the teacher (Jacobs, 2016). It is also pointed out that

The professional work environment is needed for implementation of the objective of pedagogical practice development of students' professional knowledge and skills in the process of organising and leading learning at school. In its turn, the objective of student's individual development is influenced by his/her life experience, values and attitudes (Strode, 2013, p. 84).

From all the above, it is necessary to have enough time, both to change the preconceived concepts and to implement and see results of this training process (Altun \& Yücel-Toy, 2015), although this methodology may promote conscious, intentional and motivated autonomy of students in their pedagogical practice.

\subsection{For Teachers}

For teachers, there are several challenges to be faced, and, as referred by Vaughan and Burnaford (2016), "Action research for practitioners is both an insider and outsider activity that is not always a comfortable position for teacher educators in colleges of education" (p. 295).

In sum, in research terms, the following are listed as challenges to be faced by these professionals: the shift in their teaching culture, the logistical management of the conditions of PAR implementation, and greater uncertainty, which translates into less control in the educational process.

Regarding the shift in teachers' educational culture, the sharing of hierarchical power, whose reshaped and less static dynamics is present in PAR, may entail a reformulation, over time, of the traditional roles assigned to the teacher and the student (Jacobs, 2016; Kindon \& Elwood, 2009; Rubin, Ayala, \& Zaal, 2017).

PAR implementation involves, therefore, profound changes in teaching and training (Corpa et al., 2010; Gibbs et al., 2017), namely in the relationship with other stakeholders (Kindon \& Elwood, 2009), in a greater emotional involvement (Kindon \& Elwood, 2009), and even in the possibility of a potential overload of time tasks (Barbre et al., 2013; Mendonça et al., 2015; Strode, 2013):

Would there be some extra work? Yes, there would, but it would not be so voluminous that it is undoable, and the benefits would instill a habit that would improve a career trajectory. At best, it would have the effect of training a teacher to consider classroom-based research a natural component of their practice. Rather than feeling stuck and unable to move forward, teachers would have the tools to take a much deeper look at who they are professionally and move forward. When we consider the sheer volume of teacher attrition over the first 5 years of a teaching career, we consider implementing critical reflection though action research to be an approach that reflects professional responsibility (Barbre et al., 2013, p. 5).

This context implies a new logistical management of the conditions for implementing PAR at different levels.

On the one hand, there is the issue of meeting deadlines (Kindon \& Elwood, 2009): "It also involves quite intense pastoral supervision and mentoring $[\ldots]$ there is a tension between the academic timetable and need for students to submit assignments (and lecturers to submit grades) on particular dates" (p. 26).

On the other hand, there is also greater uncertainty and less control in the educational process on the part of the teacher, 
whose central function is to stimulate participation and to motivate students in this more plasmatic and flexible context that generates greater uncertainties (Kindon \& Elwood, 2009; Mendonça et al., 2015). This results in the need for greater flexibility in the management of the teaching-learning process, which itself generates unpredictability that entails greater difficulty in systematic follow-up. As pointed out by Gibbs et al. (2017), it "include[s] a lack of reporting on the AR [action research] stages or cycles in a way that allows others to analyse the study systematically" (p. 13), which may run counter to preconceived ideas and/or expectations of both teachers and students (Kindon \& Elwood, 2009).

All this implies that teachers may be able, on the one hand, to explain and explicit the process and, on the other hand, to motivate students to participate actively, while simultaneously recognising the authority of the teacher, as well as their limitations (Altun \& Yücel-Toy, 2015). Although these actions reinforce the role of teachers as instigators of this PAR process (Gibbs et al., 2017), it is also critical that the institutional context provides the necessary conditions and resources (Jacobs, 2016) that allow the path to be corrected during its implementation (Strode, 2013).

\subsection{For Institutions}

At the institutional level, academic legitimacy and the articulation between different curricular units, as well as the conditions of implementation and control of this process, seem to be vital elements.

Low academic legitimacy seems to be one of the aspects hindering PAR's choice (Anderson, 2017; Downs, 2017; Gibbs et al., 2017; Lewis, 2004; Riecken, Strong-Wilson, Conibear, Corrine, \& Riecken, 2005; Vaughan \& Burnaford, 2016; Young, 2017).

According to Gibbs et al. (2017), there is the need to develop a curriculum that incorporates the academic identity itself, and the need for institutional support in staff development, and the role of academic leaders is vital in this whole process (Vikstrom et al., 2016).

There is, therefore, the need to flee from the existing orthodoxy (Vaughan \& Burnaford, 2016; Kindon \& Elwood, 2009), which entails an articulation between different curricular units (Walker \& Loots, 2017), "rethinking traditional views of scientific knowledge characterised by hierarchies and singular disciplines" (p. 14).

This process also implies that institutions rethink their own conditions of implementation and control, considering aspects such as the provision of the necessary time and resources (Jacobs, 2016; Altun \& Yücel-Toy, 2015), that they rethink the organisation and the coherence of the program (Strode, 2013) or that they consider the number of students per class in an appropriate way (Altun \& Yücel-Toy, 2015), insofar that, according to PAR features, this number cannot be too high. All of the elements mentioned are critical in creating an environment conducive to training through PAR.

\section{Final Remarks}

The implementation of PAR in a higher education context has to face a very difficult environment within the traditional academic culture, which tends to be quantitative, unidirectional, thought in a top-down way, within the framework of traditional power relationships, which emerge from expectations in higher education (Anderson, 2017; Kindon \& Elwood, 2009). Following this research logic necessarily implies a break with this more traditional perspective of doing research in higher education. As suggested by Gibbs et al. (2017),

Changes in higher education policy, driven by an explicit metrics of student satisfaction and the need for students to engage in their learning whilst registered at a higher education institution, argue for strong, practice-based evidence for what teaching can achieve. In an economic consumeristic model of higher education, an unjustified and holist concept of edification is seemingly not satisfactory. Evidence of how practice can be improved and its impact on the learning of students (and staff) is becoming critical to the changing character of higher education and its accountability to both government and students (p. 14).

Notwithstanding all the difficulties at the level of students, teachers and even institutions, as this paper has sought to demonstrate, the implementation of PAR can make a major contribution to improving teaching and learning in higher education institutions. It is a challenging process that may be a valuable contribution to the construction of a higher quality training process, fostering a closer approximation to the real contexts of action of the intervening subjects and a better understanding and apprehension of the underlying processes, in a logic of participation and collaborative construction.

\section{Acknowledgments}

University of the Azores, Interdisciplinary Centre of Social Sciences - CICS.UAc/CICS.NOVA.UAc, UID/SOC/04647/2013, with the financial support of FCT/MEC through national funds and, when applicable, co-financed by FEDER under the PT2020 Partnership Agreement.

The authors acknowledge the comments and suggestion by this article's editor and the anonymous reviewers. 
Author Contributions: All authors had equal contributions to this paper.

Conflicts of Interest: The authors declare no conflict of interest.

\section{References}

Almeida, J. C. F. de (2001). Em defesa da investigação-acção [In defense of action research]. Sociologia - Problemas $e$ Práticas, 37, 175-176.

Altun, S., \& Yücel-Toy, B. (2015). The methods of teaching course based on constructivist learning approach: An action research. Journal of Education and Training Studies, 3(6), 248-270. https://doi.org/10.11114/jets.v3i6.1047

Anderson, G. (2017). Participatory action research (PAR) as democratic disruption: New public management and educational research in schools and universities. International Journal of Qualitative Studies in Education, 30(5), 432-449. https://doi.org/10.1080/09518398.2017.1303211

Arends, R. I. (1999). Aprender a ensinar [Learning to teach]. Amadora: McGraw-Hill de Portugal.

Asuquo, E. F., \& Etowa, J. (2016). Participatory action research (PAR): A strategy to achieve transformational change in nursing research and policy development in Low and Middle Income Countries (LMICs). The International Journal of Health, Wellness, and Society, 6(1), 11-21. https://doi.org/10.18848/2156-8960/cgp/v06i01/11-21

Balakrishnan, V., \& Claiborne, L. (2017). Participatory action research in culturally complex societies: Opportunities and challenges. Educational Action Research, 25(2), 185-202. https://doi.org/10.1080/09650792.2016.1206480

Barbre, J. O., \& Buckner, B. J. (2013). Utilizing action research during student teaching: Should every teacher preparation program be doing this? SAGE Open, 3(1), 1-6. https://doi.org/10.1177/2158244013482468

Burmeister, M., \& Eilks, I. (2013). Using participatory action research to develop a course module on education for sustainable development in pre-service chemistry teacher education. CEPS Journal, 3(1), 59-78.

Corpa, E. A., Hito, P. D, \& Garcia, J. C. (2010). La investigación-acción-participativa. Una forma de investigar en la práctica enfermera [Participatory-action-research. A way to research in the nursing practice]. Invest Educ Enferm, 28(3), 464-474.

Costa, A. F. da, \& Machado, F. L. (1987). Meios populares e escola primária. Pesquisa sociológica num projecto interdisciplinar de investigação-acção [Working class environments and elementary school. Sociological research in an interdisciplinary action research project]. Sociologia-Problemas e Práticas, 2, 69-89.

Downs, Y. (2017) Furthering alternative cultures of valuation in higher education research. Cambridge Journal of Education, 47(1), 37-51. https://doi.org/10.1080/0305764X.2015.1102865

Esteve, J. M. (2003). Mudanças sociais e função docente [Social changes and the teaching profession]. António Nóvoa (org.). Profissão professor [Profession teacher] (2 $2^{\text {nd }}$ Ed.) (pp. 93-124). Porto: Porto Editora.

Esteves, A. J. (1986). A investigação-acção [Action research]. In A. S. Silva \& J. M. P. (Orgs), Metodologia das ciências sociais [Methodology of social sciences] ( $8^{\text {th }}$ Ed.) (pp. 251-278). Porto: Edições Afrontamento.

Gibbs, P., Cartney, P., Wilkinson, K., Parkinson, J., Cunningham, S., James-Reynolds, C., Zoubir, T., Brown, V., Barter, P., Sumner, P., MacDonald, A., Dayananda, A., \& Pitt, A. (2017). Literature review on the use of action research in higher education. Educational Action Research, 25(1), 3-22. https://doi.org/10.1080/09650792.2015.1124046

Higashida, M., Kumara, M. R. S., \& Illangasingha, M. G. (2015). Promoting participation of stakeholders in community-based rehabilitation in Sri Lanka: Process of action research in Anuradhapura. International Journal of Social Science Studies, 3(3), 50-60. https://doi.org/10.11114/ijsss.v3i3.732

Higgins, C. (2016). The promise, pitfalls, and persistent challenge of action research. Ethics and Education, 11(2), 230-239. https://doi.org/10.1080/17449642.2016.1185831

Ito, H. (2017). Rethinking active learning in the context of Japanese higher education. Cogent Education, 4(1), 1-10. https://doi.org/10.1080/2331186X.2017.1298187

Iwasaki, Y., Hopper, T., \& Whelan, P. (2017). Insights on inspirational education for "high-risk" youth informed by participatory action research (PAR) on youth engagement: Short communication. Journal of Education and Training Studies, 5(1), 152-158. https://doi.org/10.11114/jets.v5i1.2096

Jacobs, S. (2016). The use of participatory action research within education - benefits to stakeholders. World Journal of Education, 6(3), 48-55. https://doi.org/10.5430/wje.v6n3p48

Kindon, S., \& Elwood, S. (2009). Introduction: More than methods-Reflections on participatory action research in geographic teaching, learning and research. Journal of Geography in Higher Education, 33(1), 19-32. https://doi.org/10.1080/03098260802276474

Lewis, M. E. (2004). A teacher's schoolyard tale: Illuminating the vagaries of practicing participatory action research 
(PAR) pedagogy. Environmental Education Research, 10(1), 89-114. https://doi.org/10.1080/1350462032000173724

Marchand, T. (2017). Action learning in postgraduate research training. Action Learning: Research and Practice, 14(1), 83-95. https://doi.org/10.1080/14767333.2017.1282637

Mendonça, E. T. de, Cotta, R. M. M., Lelis, V. de P., \& Junior, P. M. C. (2015). Paradigmas e tendências do ensino universitário: A metodologia da pesquisa-ação como estratégia de formação docente [Paradigms and trends in higher education: The action research methodology as a teacher education strategy]. Interface - Comunicação, Saúde, Educação, 19(53), 373-386. https://doi.org/10.1590/1807-57622013.1024

Moch, S. D., Vandenbark, R. T., Pehler, S. R., \& Stombaugh, A. (2016). Use of action research in nursing education. Nursing Research and Practice, 2016, 1-9. https://doi.org/10.1155/2016/8749167

Radloff, J. D., Joslyn, C., \& Capobianco, B. (2016). Humanization through action research as methodology. The Qualitative Report, 21(10), 1999-2014.

Riecken, T., Strong-Wilson, T., Conibear, F., Michel, C., \& Riecken, J. (2005). Connecting, speaking, listening: toward an ethics of voice with/in participatory action research. Forum Qualitative Sozialforschung/Forum: Qualitative Social Research, 6(1), 26. http://www.qualitative-research.net/index.php/fqs/article/download/533/1155

Rubin, B. C., Ayala, J., \& Zaal, M. (2017). Authenticity, aims and authority: Navigating youth participatory action research in the classroom. Curriculum Inquiry, 47(2), 175-194. https://doi.org/10.1080/03626784.2017.1298967

Santos, D. (2016). Re-signifying participatory action research (PAR) in higher education: What does 'P' stand for in PAR? Educational Action Research, 24(4), 635-646. https://doi.org/10.1080/09650792.2015.1103658

Schneider, B., \& Daddow, A. A. (2017). Valorising student literacies in social work education: Pedagogic possibilities through action research. Pedagogy, Culture \& Society, 25(2), 157-170. https://doi.org/10.1080/14681366.2016.1233451

Sivaci, S. Y. (2017). The relationship between reflective thinking tendencies and social problem solving abilities of pre-service teachers. Journal of Education and Training Studies, 5(11), 21-31. https://doi.org/10.11114/jets.v5i11.2273

Smith, S. (2017). Reflections for postgraduate students on writing an action research thesis. ALARj., 23(1), 61-76.

Strode, A. (2013). Participatory action research for development of prospective teachers' professionality during their pedagogical practice. Discourse and Communication for Sustainable Education, 4, 80-90. https://doi.org/10.2478/dcse-2013-0007

Vaughan, M, \& Burnaford, G. (2016). Action research in graduate teacher education: A review of the literature 2000-2015. Educational Action Research, 24(2), 280-299. https://doi.org/10.1080/09650792.2015.1062408

Vikstrom, S., Bostrom, C., \& Johannsen, A. (2016). Pedagogic leadership in higher education using participatory action research strategies - Illustrative cases from three pedagogical development contexts. Dentistry, 6(8), 388. https://doi.org/10.4172/2161-1122.1000388

Walker, M., \& Loots, S. (2017). Transformative change in higher education through participatory action research: A capabilities analysis. Educational Action Research, 26(1), 166-181. https://doi.org/10.1080/09650792.2017.1286605

Worthen, M., Onyango, G., Wessells, M., Veale, A., \& McKay, S. (2013). Facilitating war-affected young mothers' reintegration: Lessons from a participatory action research study in Liberia, Sierra Leone, and Uganda. International Journal of Social Science Studies, 1(1), 145-149. https://doi.org/10.11114/ijsss.v1i1.43

Yigit, C., \& Bagceci, B. (2017). Teachers' opinions regarding the usage of action research in professional development. Journal of Education and Training Studies, 5(2), 243-252. https://doi.org/10.11114/jets.v5i2.1878

Young, L. B. (2017). PhotoVoice participatory action research for the communication classroom. Communication Teacher, 31(4), 226-230. https://doi.org/10.1080/17404622.2017.1358381

Zhang, Q., \& Amundsen, C. (2015). Exploring the experiences of faculty-led teams in conducting action research. Canadian Journal for the Scholarship of Teaching and Learning, 6(1), 1-20. https://doi.org/10.5206/cjsotl-rcacea.2015.1.8

\section{Copyrights}

Copyright for this article is retained by the author(s), with first publication rights granted to the journal.

This is an open-access article distributed under the terms and conditions of the Creative Commons Attribution license which permits unrestricted use, distribution, and reproduction in any medium, provided the original work is properly cited. 